\title{
Development and Realization of Base Isolation System for High-Rise Buildings
}

\author{
Tsutomu Komuro ${ }^{1}$, Yasuhiro Nishikawa ${ }^{2}$, Yuichi Kimura ${ }^{2}$ and Yuji Isshiki ${ }^{2}$
}

Received 28 December 2004, accepted 14 May 2005

\begin{abstract}
High-rise buildings with a base isolation system have been realized by investigating the aspect of practical applicability through the identification and addressing of the difficulties involved in actual design applications. Among the base-isolated buildings we have designed so far, the Sendai MT Building is the first base-isolated building with a height exceeding $60 \mathrm{~m}$ in Japan, and the Thousand Tower was the tallest base-isolated residential Tower in Japan when completed. These examples show that the appropriate utilization of the base isolation system with high-strength materials and a long-span structure system makes it possible to endow high-rise buildings not only with strong seismic performance but also architectural design flexibility. This paper provides empirical evidence that the base isolation system can properly work for high-rise buildings. According to the seismic data obtained from the seismographs in the Sendai MT Building when the Off-Miyagi earthquake struck on May 26, 2003, the base isolation system of this high-rise building performed as effectively as designed.
\end{abstract}

\section{Introduction}

In base-isolated structures, the large amount of energy input by an earthquake is mainly absorbed by the base isolation devices. Hence, the base isolation system has been widely recognized as one of the most effective systems for minimizing damage to superstructures so that only a limited amount of repair should be required even after a severe earthquake. Yet despite its great potential, this system had been regarded as ineffective in high-rise buildings, and was thus applied only to low-rise buildings with a natural period shorter than 1 second.

In order to achieve high-rise buildings with high seismic performance by utilizing the base isolation system, the following problems had to be addressed.

(1) Unclear response reduction effect of base isolation on high-rise buildings

(2) Possibility that base isolation system in high-rise buildings may result in poor habitability due to swinging during strong wind

(3) Possibility that adoption of base isolation system may cause significant increase in construction cost

(4) Unknown response characteristics and stability of large-size rubber bearing subjected to tensile forces

\section{Effect on high-rise buildings}

With regard to problem (1) mentioned above in the in-

\footnotetext{
${ }^{1}$ Engineer, Structural Engineering Group, Design

Division, Taisei Corporation, Japan.

E-mail:komuro@arch.taisei.co.jp

${ }^{2}$ Engineer, Structural Engineering Group, Design

Division, Taisei Corporation, Japan.
}

troduction, parametric analyses (Ogura et al, 1997b) indicate that the response reduction effect can be gained by utilizing the base isolation system regardless of the range of the superstructure's natural period, that is whether the designed building is a low-rise or high-rise structure.

Figure 1 shows the 2-mass model of the base isolated structure, representing the superstructure and the base isolation story as two mass-points. The superstructure is assumed to use a reinforced concrete frame and the base isolation system to be the hysteretic energy absorption type. The force-displacement relation and the hysteretic rule of the springs are shown in Fig. 2. Using this simple model, Ogura and his team conducted many parametric studies using as parameters the yielding shear coefficients of the superstructure and the base isolation, the natural period of the superstructure, the natural period of the base isolation after yielding, the kinds and the intensity of seismic waves, and the ratio of the weight of the base isolation to that of the superstructure. Some of these analytical results are shown and the response reduction effect of the base isolation on high-rise buildings is discussed in this report.

The yielding shear coefficients of the superstructure and the base isolation are constants of 0.2 and 0.03 , re-

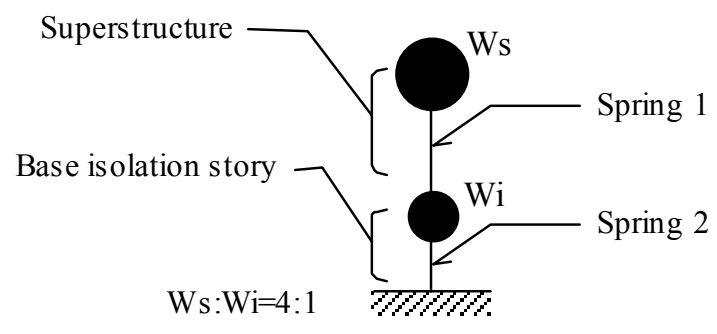

Fig.1 Analysis model. 
spectively, and the natural period of the base isolation after yielding is set to 5.0 seconds. The parameter is the natural period of the superstructure, varied in the range of 0.2 to 5.0 seconds in 0.2 increments. Taking into account the actual rate of the superstructure's weight to that of the base isolation story, the ratio is assumed to be $\mathrm{Ws}: \mathrm{Wi}=$ 4:1. The dynamic analyses were carried out using the ground acceleration waves, El Centro (1940-NS) and the artificial seismic wave of BCJ-L2 (which has a max. velocity of $0.574 \mathrm{~m} / \mathrm{s}$ ). The wave of El Centro amplified with the max. velocity of $1.00 \mathrm{~m} / \mathrm{s}$ was chosen because several intensity levels ( $\max$. velocities $=0.25,0.50,0.75$, $1.00 \mathrm{~m} / \mathrm{s}$ ) were studied and the intensity of $1.00 \mathrm{~m} / \mathrm{s}$ sufficiently influences all models with the varied natural periods to cause large response.

Figure 3 and Fig. 4 show the response displacement of the superstructure and that of the base isolation story, respectively, corresponding to the varied natural period of the superstructure. In Fig. 3, the response of the vertical axis is defined to be the ratio of the response displacement to that in the case without the base isolation system.
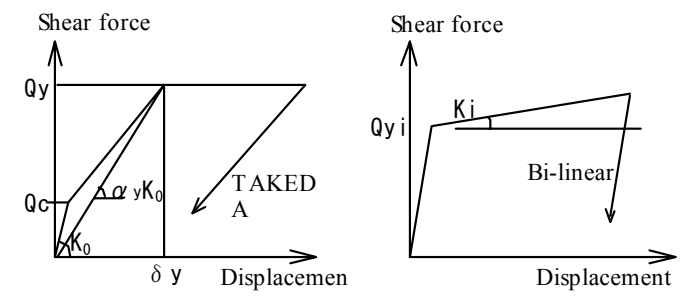

$\underline{\text { Spring } 1}$

$\underline{\text { Spring } 2}$

Fig.2 Properties of springs.

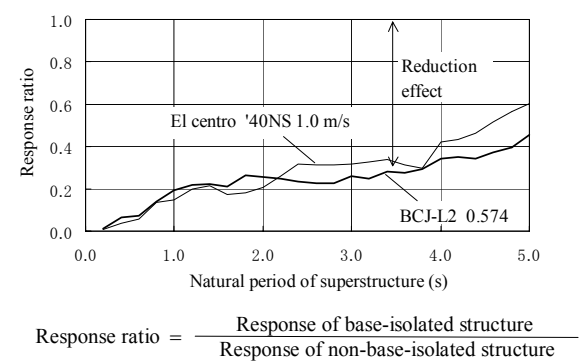

Fig.3 Response displacement of superstructure.

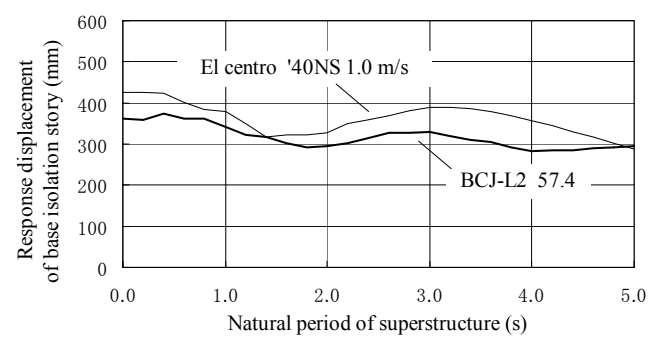

Fig.4 Response displacement of isolation story.
Figure 3 shows that the response reduction tends to decrease in proportion to the increase in the natural period of the superstructure. However, even when the natural period is 3-4 seconds, the response displacement can be reduced up to around $30-40 \%$ of the case without the base isolation. The response displacement of the base isolated superstructure remained less than the yield displacement ( $\delta y)$, while the response displacement of the non-isolated superstructure often exceeded the yield displacement. Moreover, the response displacement of the base isolation story is approximately $300-400 \mathrm{~mm}$, so the response of the base isolated structure is considered to be very stable.

Judging from these results, if the design of the yield shear force and the stiffness after the yield of the base isolation story are appropriate, strong seismic performance can be achieved even for high-rise buildings.

\section{Base isolation devices}

The improvement in dynamic performance depends on the force-displacement relation in the base isolation story. In order to reduce the dynamic response regardless of the natural periods of superstructures, the innovative base isolation system, called Hybrid TASS system (Hybrid TAISEI Shake Suppression system), has been developed. This system is composed of two types of bearings, such as rubber bearings and sliding bearings. In order to reduce the dynamic response due to an earthquake in a high-rise building, whose natural period is basically long, the stiffness of the base isolation story needs to be so soft that the effective natural period should be long. On the other hand, the initial soft stiffness of the ordinal base-isolation system might result in poor habitability due to swinging during strong winds (see Fig. 5).

This contradictory problem, which is denoted as problem (2) in the introduction, can be solved with the Hybrid TASS system. Figure 5 shows the typical force-displacement relation of the Hybrid TASS system. By setting the yield shear force of the base isolation story larger than the design wind force, the initial stiffness of the whole structure can be kept almost the same as that of a building without the base isolation system. At the same time, strong seismic performance in case of a huge earthquake is obtained as the stiffness after the yield is particularly soft.

Moreover, the Hybrid TASS system is also advantageous in terms of costs. Figure 6 shows the comparison between the Hybrid TASS system and another typical example of the base isolation system. In the other system, the dampers such as the steel or lead energy absorption devices are inevitable besides the isolators under the columns, while the sliding and rubber bearings are located only under the columns in the Hybrid TASS system. Hence, by applying the Hybrid TASS system as the base isolation system, high-rise buildings with strong seismic performance can be achieved without a large increase in construction costs. 


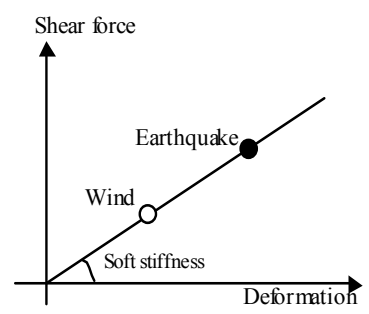

Ordinal System

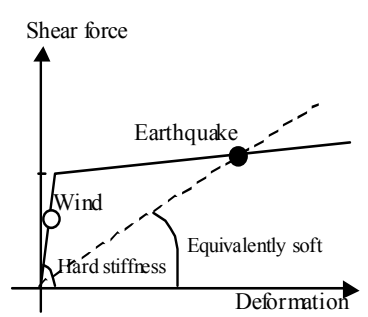

$\underline{\text { Hybrid TASS System }}$
Fig.5 Force-displacement relation.

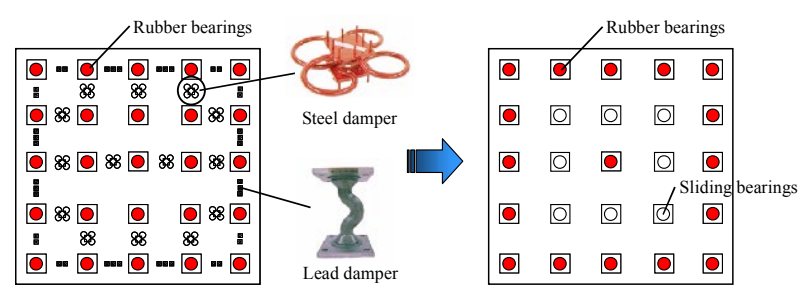

Fig.6 Comparison of Hybrid TASS system and ordinal base isolation system.

\section{Tests on tensile property of rubber bearing}

In the design of a slender high-rise building, the uplift due to overturning and vertical forces during a large earthquake might act on the isolators, especially at the corners. However, the response characteristics and stability of large size rubber bearings subjected to tensile force were unknown (problem (4)). In order to understand the tensile properties of large rubber bearings, tensile loading tests (Muramatsu et al. 2001) were carried out (see Fig. 7). Figure 8 shows a test specimen with a diameter of $1200 \mathrm{~mm}$. The relation between tensile and shear strain is shown in Fig. 9, which plots the test results of these large size tests, along with the tensile and shear strain results of bearings with a smaller diameter of 500 $\mathrm{mm}$ from other tests (Takayama 1995). From the results of the bearings with a small diameter, the failure limit was expected to approximate the line shown in Fig. 9. However, in the tests of the large scale, the failure was observed at the tensile strain of $50 \%$ and the shear strain of $300 \%$, which is much less than the expected limit of the small scale tests. There is thus a large difference in the failure limit due to the scale effect.

Considering this tendency, the region of tensile stain less than $10 \%$ and the region of shear strain less than $300 \%$ were selected as the design criteria. With these design criteria, the response tensile strain can be kept sufficiently lower than the failure limit.

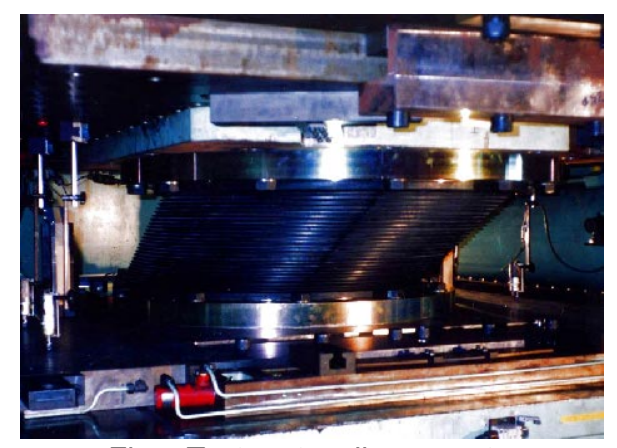

Fig.7 Test on tensile property.

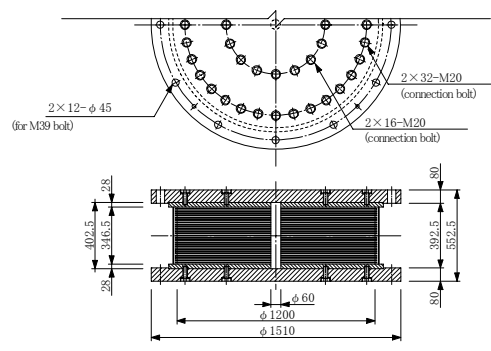

Fig.8 Test specimen.

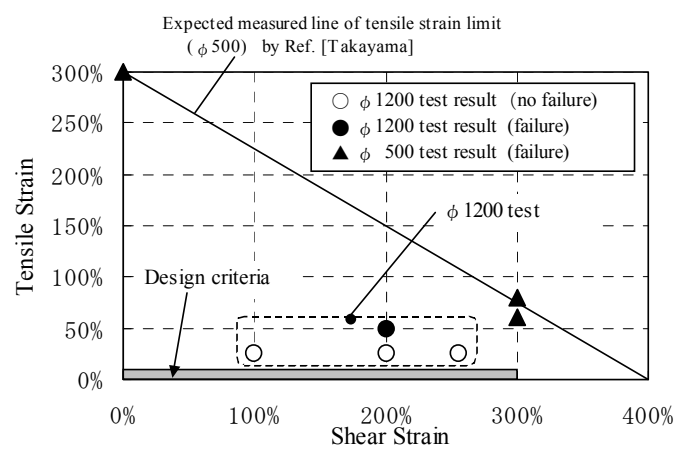

Fig.9 Relation of tensile and shear strain.

\section{Design of high-rise buildings with hybrid tass system}

\subsection{Sendai MT Building}

The Sendai MT Building is an 18-story office building with a height of $84.9 \mathrm{~m}$ located in Sendai City, Miyagi Prefecture (Ogura et al. 1997a). This building is Japan's first base-isolated building with a height exceeding $60 \mathrm{~m}$ (see Fig. 10 and Fig. 11).

The structural features of this building are as follows.

1) Use of the high-strength materials such as concrete with compressive strength of $60 \mathrm{~N} / \mathrm{mm}^{2}$ and SD 490 re-bars for the longitudinal reinforcement of the beams and the columns. 


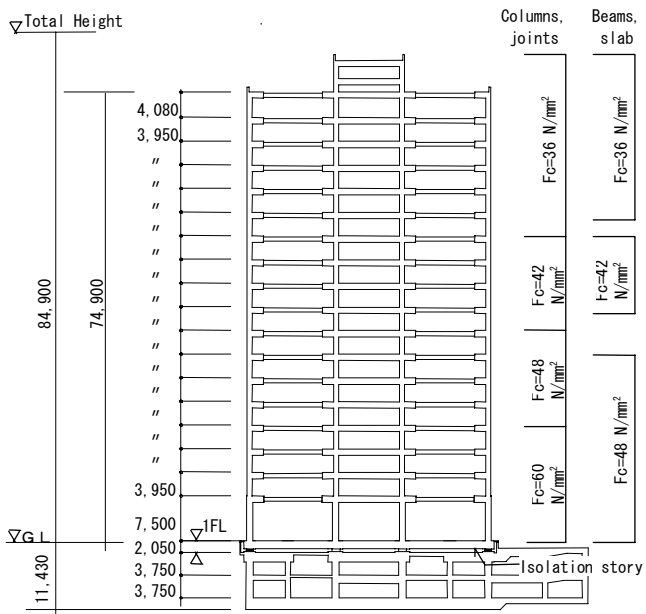

Fig.10 Frame elevation.

2) Application of hybrid structure beams for $15 \mathrm{~m}$-long spans. These beams consist of steel in the mid part and reinforced concrete at both ends of the beam.

3) High-rise building with base isolation system for strong seismic performance.

The client required strong seismic performance and maintainability after a large earthquake. To meet these requirements, the application of the base isolation system, Hybrid TASS, was examined. Moreover, in order to secure large office space (see Fig. 12), a long-span structure system and high-strength materials were used. Figure 10 shows the frame elevation. The columns (sectional dimensions of typical column: $850 \times 850 \mathrm{~mm}$ ) and the beams (sectional dimensions of typical beam: $650 \mathrm{x}$ $1050 \mathrm{~mm}$ ) were pre-cast members to ensure the quality of the structure and to make the construction term as short as possible.

Figure 13 shows the arrangement of the isolation devices at the isolation story below the first floor. The ratio of the sliding bearings among all the bearings under the columns was designed so that the yield force might be larger than the wind force. The yielding base shear coefficient of the base isolation is designed to be $3.7 \%$. The shape and rubber stiffness of the rubber bearings were designed to make the stiffness after the yield soft. The natural period of the base isolation after the yield is approximately $5 \mathrm{~s}$. The sliding bearings were installed mainly under the inner columns, where the fluctuation of the axial force due to seismic forces is relatively small.

Dynamic analyses were conducted to confirm the target seismic performance, using several earthquake waves. The analysis model was a lumped-mass-model consisting of 21 masses and the springs connecting the masses are the equivalent shear type. The input levels of the waves are categorized from level 1 to level 3, considering occurrence probability during the building usage period. The waves of levels 1, 2 and 3 are accelerations

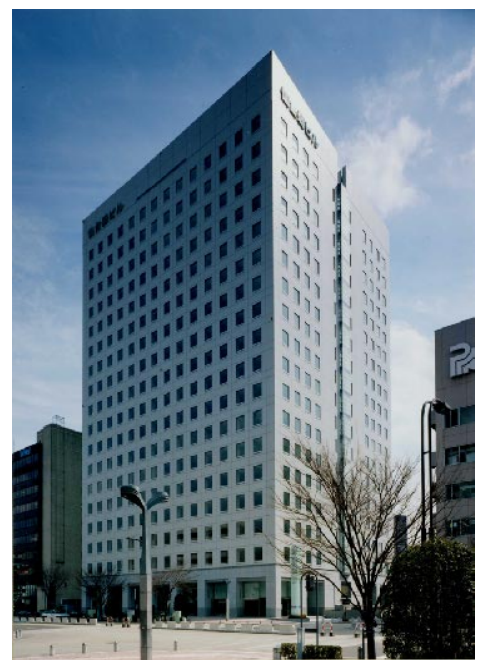

Fig.11 Sendai MT Building.

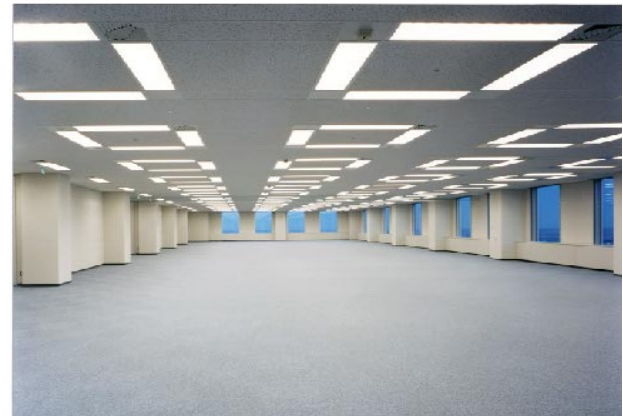

Fig.12 Sendai MT Building (office space).
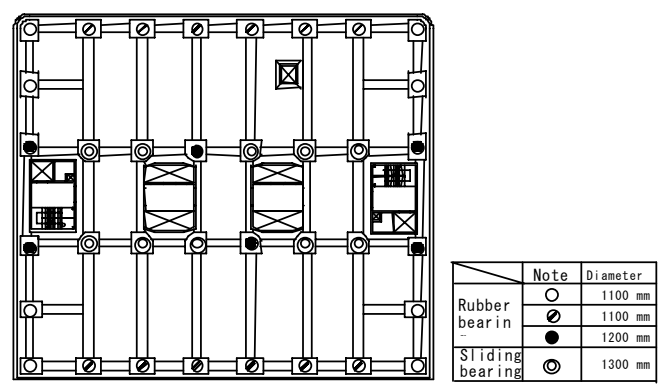

Fig.13 Arrangement of isolation.
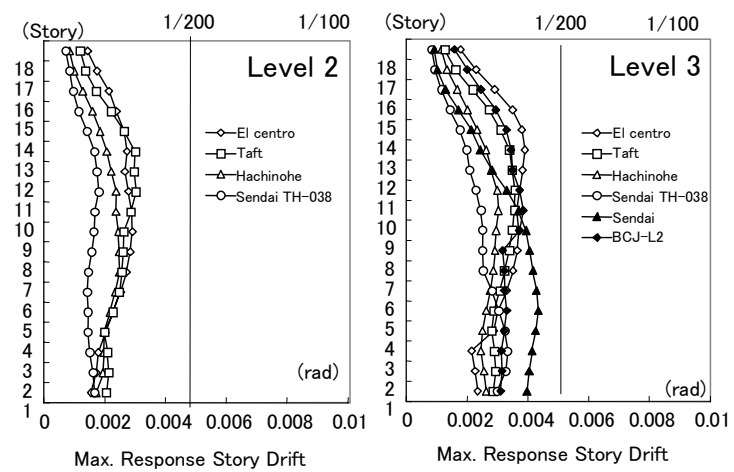

Fig.14 Maximum response story drift. 
amplified with the max. velocity of $0.25,0.50$ and 0.75 $\mathrm{m} / \mathrm{s}$, respectively, using the recorded waves of El Centro (1940 NS), Taft (1952 EW) Hachinohe (1968 NS) and Sendai TH-038 (1978 EW). The artificial seismic wave of BCJ-L2 (max. velocity of $0.574 \mathrm{~m} / \mathrm{s}$ ) was also added to level 3. From the results of the level 1 analyses, the design base shear coefficient of the superstructure is defined to be $8 \%$. Figure 14 shows the maximum response story drift angle of levels 2 and 3. For level 2, the drift angles are less than 1/330 and for level 3 less than $1 / 230$. These results indicate satisfaction of the seismic design targets and strong seismic performance.

\subsection{Thousand tower}

Thousand Tower. a residential tower situated in Kawasaki City, Kanagawa Prefecture, is a reinforced concrete structure with 41 stories above ground (Kawabata et al. 2001) (see Fig. 15). The base isolators are placed at the isolation story below the first floor. Figures 16 and 17 show the frame elevation and the structural plan, respectively. The total height is $135.0 \mathrm{~m}$ and the aspect ratio is 3.83 in the $\mathrm{Y}$ direction, making this building a relatively slender structure. The yielding base shear coefficient of the base isolation and the design base shear coefficient of the superstructure are designed to be $3.5 \%$ and $6.5 \%$, respectively.

The pre-cast and pre-stressed concrete beams as shown in Fig. 18 are used for the 12-m span. A pre-stressing steel tendon is arranged at the clear mid-span of the beam and the longitudinal reinforcement of the steel bars is passed through the beam and developed at the beam-column joints. Adoption of this long span system made it possible to eliminate columns in the residential area.

High-strength concrete with strengths up to 100 $\mathrm{N} / \mathrm{mm}^{2}$ is used for the columns and high-strength re-bars (SD 490, USD 685) are used for the longitudinal reinforcement of the beams and the columns. By using these high-strength materials, the number of structural members and their cross-section can be reduced, so that the effective architectural space can be used for the planning. The dimensions of the typical column are $1000 \times 1000$ $\mathrm{mm}$ and the dimensions of the typical beam are $650 \times 850$ $\mathrm{mm}$.

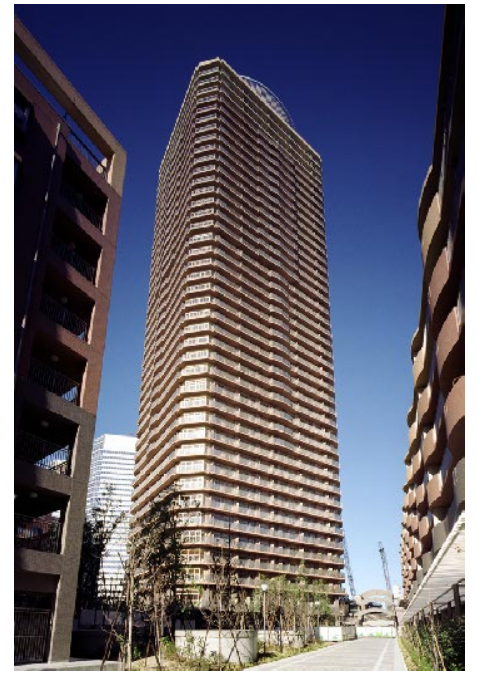

Fig.15 Thousand Tower.

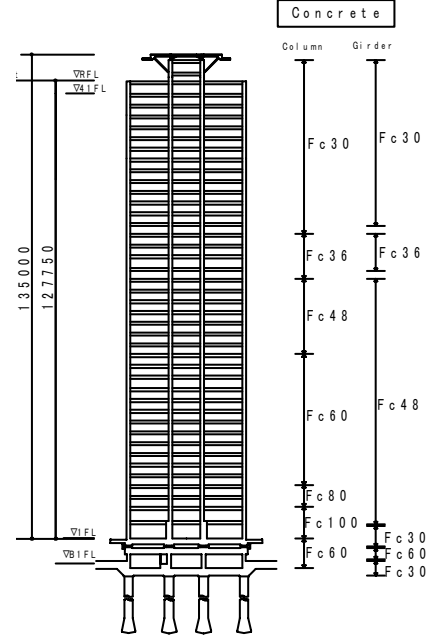

Fig.16 Frame elevation.

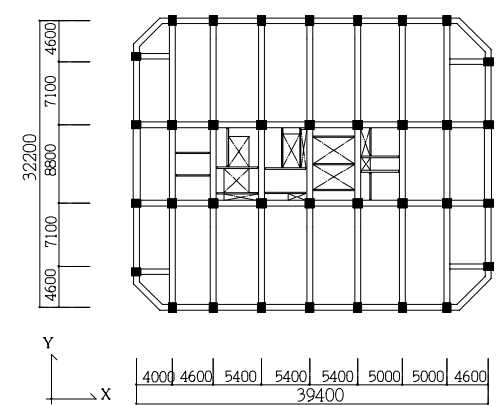

Fig.17 Structural plan.

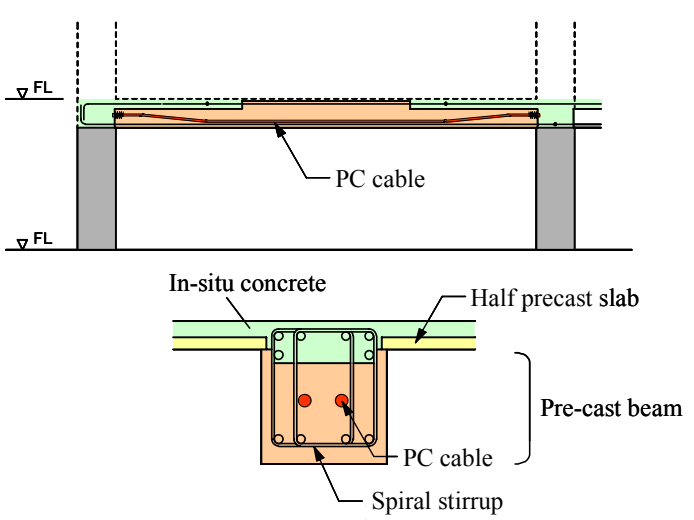

Fig.18 Pre-cast and pre-stressed beam. 
The dynamic analyses were conducted using several artificial waves (see Table 1). Artificial wave $\mathrm{H}$ is based on the seismic activity and the ground conditions at the building location. The analysis model is the equivalent shear system, composed of concentrated masses and story shear springs. The relation between the lateral resistance and the story drift are derived from a non-linear static incremental loading analysis, and approximated to a tri-linear relation. The degrading stiffness model proposed by Takeda is used for the hysteresis model. The damping of the superstructure is assumed to be proportional to the instantaneous stiffness, and to be $3 \%$ with respect to the superstructure's fundamental natural period.

The level 2 maximum response of the isolation story in the $\mathrm{Y}$ direction is shown in Fig. 19 and the level 2 maximum response story drift angle in the $\mathrm{Y}$ direction is shown in Fig. 20. Compared with the response of the

Table 1 Seismic waves.

\begin{tabular}{|c|c|c|c|}
\hline & $\begin{array}{c}\text { Level 1 } \\
\left(\mathrm{m} / \mathrm{s}^{2}\right)\end{array}$ & $\begin{array}{c}\text { Level 2 } \\
\left(\mathrm{m} / \mathrm{s}^{2}\right)\end{array}$ & $\begin{array}{c}\text { Level 3 } \\
\left(\mathrm{m} / \mathrm{s}^{2}\right)\end{array}$ \\
\hline BCJ-L2 & - & 0.574 & - \\
\hline Artificial wave H & 0.237 & 0.474 & 0.595 \\
\hline
\end{tabular}

Shear force $[\mathrm{kN}]$

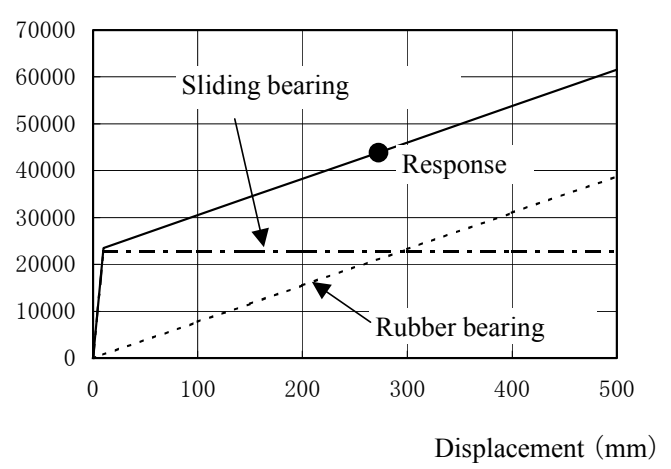

Fig.19 Maximum response of isolation story.

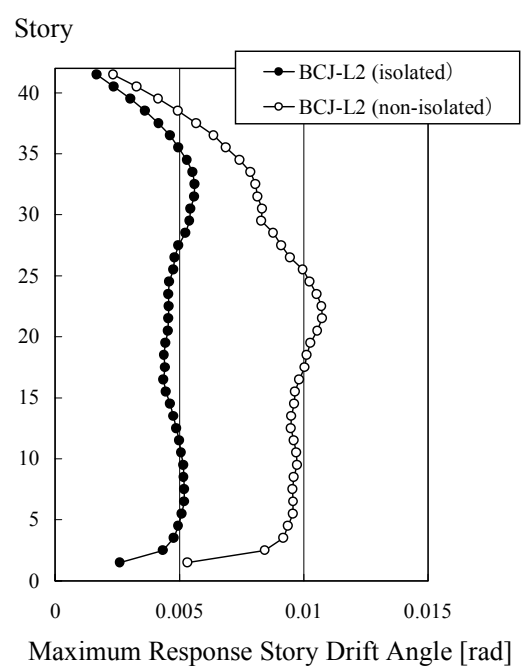

Fig.20 Maximum response story. non-isolated model, the responses are effectively reduced by the base isolation system.

Using the shear-flexural model under the simultaneous application of horizontal and vertical excitations, the influences of the rocking effect and the response tensile stress of the rubber bearings were studied additionally. Under the Level 3 seismic motion, tensile stress occurs in the 45 degree direction case, although the corresponding tensile strain is approximately $1.7 \%$, which satisfies the design criteria.

\section{Seismic record of Off-Miyagi quake, May 26, 2003}

The seismic data were obtained from the seismographs set at the isolation story and the 1st, 10th and 18th stories of the Sendai MT Building, when the Off-Miyagi earthquake occurred on May 26, 2003 The maximum accelerations at these floors are listed in Table 2 and the acceleration waves in the E-W direction are shown in Fig. 21. The accelerations of the isolation story are thought to be very close to that of the ground, because the stiffness of the basement is very large. Compared with the accelerations of the isolation story and the 1st story, reduction in the horizontal accelerations (NS and EW directions) was found.

Table 2 Maximum accelerations.

\begin{tabular}{|c|c|c|c|}
\hline & $\begin{array}{c}\text { NS Dir. } \\
\left(\mathrm{mm} / \mathrm{s}^{2}\right)\end{array}$ & $\begin{array}{c}\text { EW Dir. } \\
\left(\mathrm{mm} / \mathrm{s}^{2}\right)\end{array}$ & $\begin{array}{c}\text { UD Dir. } \\
\left(\mathrm{mm} / \mathrm{s}^{2}\right)\end{array}$ \\
\hline 18th Floor & 572 & 820 & 1040 \\
10th Floor & 507 & 796 & 683 \\
1st Floor & 357 & 550 & 486 \\
\hline Isolation Story & 542 & 699 & 473 \\
\hline
\end{tabular}
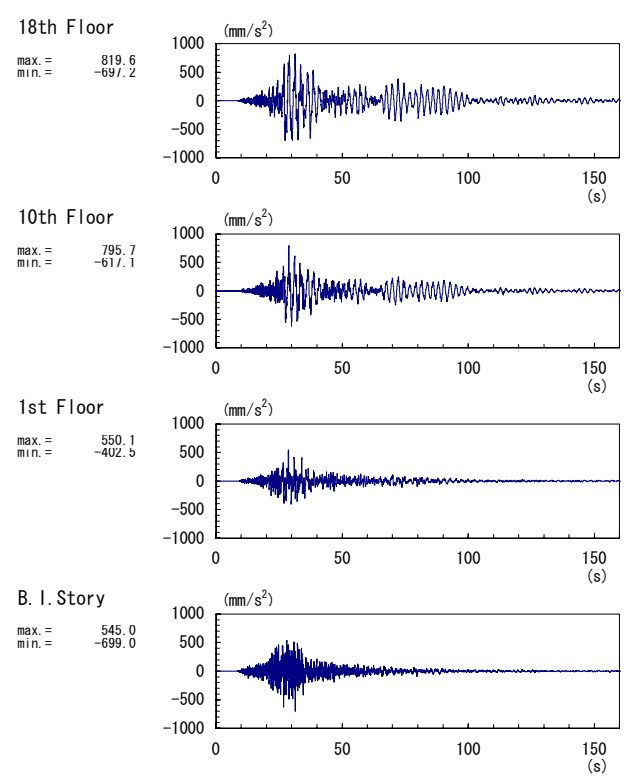

Fig.21 Acceleration waves in E-W direction. 


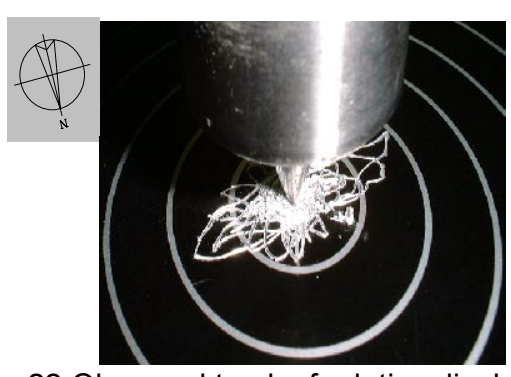

Fig.22 Observed track of relative displacement.
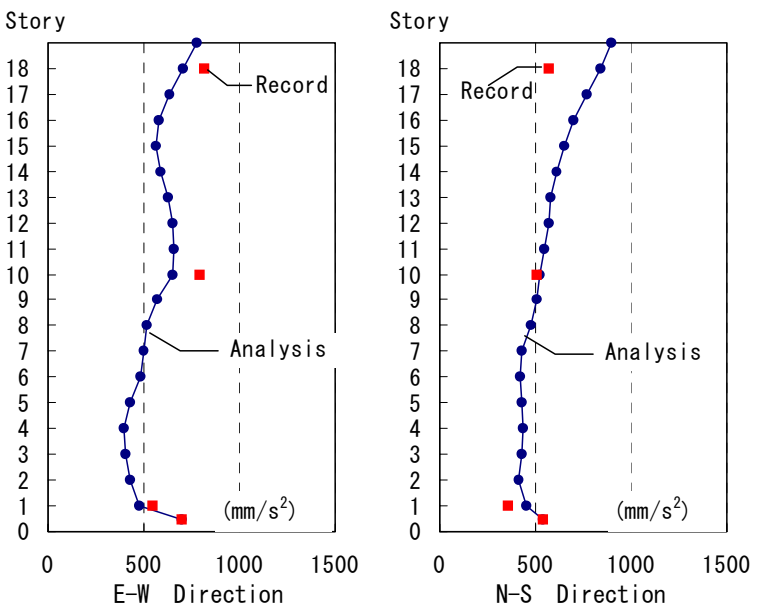

Fig.23 Comparison of analyses and records.

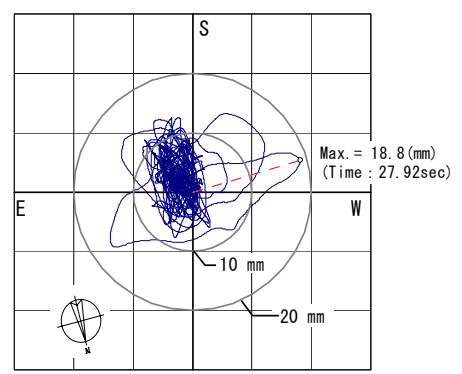

Fig.24 Analyzed displacement track.

Figure 22 shows the observed track of the relative displacement between the 1st floor and the floor below, which means the displacement of the isolation story. From this result, the maximum displacement of the isolation story is found to be about $20 \mathrm{~mm}$ and there is no final displacement. Considering with the relation between the force and the displacement in the design, sliding occurred and the isolation system is considered to have functioned well.

Dynamic analyses using the design model were carried out using the recorded acceleration waves. Figure 23 shows the comparison of the analyzed and recorded maximum acceleration. Figure 24 shows the displacement track of the isolation story from the analyses. Good agreement between the analyses and the records can be seen in these charts.

These data and analyses indicate that the base isolation system performed effectively in the high-rise building that was examined and that the design analysis model is adequate.

\section{Conclusions}

1. Application of base isolation to high-rise buildings is innovative, calling for a design approach that differs from the procedures commonly applied to low-rise types of construction.

2. Several actual design problems have been resolved for the applicability of the base isolation system to high-rise buildings.

3. Using high-strength materials and a long-span structure system, the Sendai MT Building and Thousand Tower have not only high seismic performance but also design planning flexibility.

4. The recorded data of the seismographs and the analyses show that the base isolation system acted effectively in the Sendai MT Building when the Off-Miyagi earthquake occurred on May 26, 2003.

\section{References}

Kawabata, I., Takayama, M., Nishikawa, Y., Kimura, Y., Yamazaki, E. and Isshiki, Y. (2001). "Structural Design of High-rise Building with Base Isolation System Using Elastic Sliding Bearings and Rubber Bearings." AIJ Journal of Technology and Design, (12), 99-104.

Muramatsu, Y., Nishikawa, I., Kawabata, I., Takayama, M. and Kimura, Y. (2001). "Tensile Property of Large-sized Natural Rubber Bearing." AIJ Journal of Technology and Design, (12), 53-56.

Ogura, K., Kawabata, I., Hara, T., Komuro, T., Hara, K. and Terashima, T. (1997a). "Sendai MT Building." Building Letter, 1-8.

Ogura, K. Kawabata, I., Komuro, T., Soya, K. and Terashima, T. (1997b). "Seismic Response Characteristics of High-rise Buildings with Base Isolation System." AIJ Journal of Technology and Design, (5), 47-51.

Takayama, M. (1995). "Ultimate Capacity of Natural Rubber Bearings Used in Seismic Isolation System." AIJ Journal of Technology and Design, (1), 160-165. 